\title{
Knowledge, attitudes and practice regarding copper intrauterine contraceptive devices among doctors in Malaysia
}

\author{
Kah Teik Chew, Norsaadah Salim, Muhammad Azrai Abu, \\ Abdul Kadir Abdul Karim
}

Department of Obstetrics and Gynaecology, Universiti Kebangsaan Malaysia Medical Centre, Kuala Lumpur, Malaysia

\section{Correspondence to}

Dr Kah Teik Chew, Department of Obstetrics and Gynaecology, Universiti Kebangsaan Malaysia Medical Centre, Kuala Lumpur 56000, Malaysia; drchewkt@ gmail.com

Received 17 July 2017 Revised 7 May 2018

Accepted 14 May 2018 Published Online First

1 June 2018
Check for updates

To cite: Chew KT, Salim N, Abu MA, et al. BMJ Sex Reprod Health 2018;44:200-206.

\begin{abstract}
Background and objective Intrauterine contraceptive devices (IUDs) are an important method to reduce unmet need for family planning and for prevention of unintended pregnancy. However, IUD use in Malaysia is still low. Doctors play a major role in influencing IUD uptake among women. This study was designed to evaluate doctors' knowledge, attitudes and perceptions towards IUDs and factors associated with their current practice.

Methods A questionnaire was mailed to public and private contraceptive providers who practise in Kuala Lumpur, Malaysia.

Results A total of 400 doctors were invited and $240(60 \%)$ of them responded to the survey. Of the respondents, 161 (65.9\%) were from the public or government sector and 89 (34.1\%) were from the private sector. The knowledge score of doctors was classed as 'average', and correlated well with their previous training level, working position, number of patients seen in a week and number of contraceptive methods available in their facilities. The age, gender, working duration, availability of IUDs in the premises and number of IUD insertions in a month were not statistically associated with the providers' knowledge. The use of IUDs was low, especially among private doctors, and was significantly related to their knowledge of the method. Knowledge scores, perception and practice were significantly lower in the private sector.
\end{abstract}

\section{INTRODUCTION}

Unmet need for family planning is defined as the percentage of women who want to stop or delay childbearing but are not using contraception. Globally, about 12\% of married or in-union women are estimated to have an unmet need for family

\section{Key messages}

- In the Kuala Lumpur study cohort, only $45 \%$ of private doctors and $63 \%$ of government doctors believed that the intrauterine device (IUD) is an effective contraceptive method.

- Almost $30 \%$ of the doctors were not aware that copper IUDs can be used as emergency contraception.

- Government doctors had a significantly higher knowledge score than those in the private sector.

- Only a minority of doctors $(6.7 \%)$ did not recommend IUDs to women.

planning. ${ }^{1}$ The unmet need was reported to be $22 \%$ in developing countries, ${ }^{1}$ but in Malaysia unmet need was reported to be as high as $25 \% .^{2}$ When use of contraception is low, unintended pregnancy rates are shown to be high, increasing the risk of maternal morbidity and mortality. ${ }^{3}$

Research has demonstrated that longacting reversible contraception methods such as copper intrauterine devices (IUDs) are a cost-effective and sustainable way of reducing unmet need and unplanned pregnancy in developed or developing countries. ${ }^{3}$ The IUD is an effective method of non-hormonal contraception and is reversible, unlike female sterilisation. ${ }^{4}$ Around the world, rates of IUD usage are high in countries such as Uzbekistan (50\%), Vietnam (31\%), China (41\%), Egypt (36\%) and Finland $(23 \%),{ }^{1}$ but in Malaysia the rate of IUD usage was reported as only $5.4 \%$ in the year $2015^{1}$. In Malaysia, family planning services are available from doctors in either public or private sectors. The the 
most common contraceptive method in Peninsular Malaysia is hormonal contraceptive pills (contraceptive prevalence rate of 14.0) as compared with IUDs (contraceptive prevalence rate of 4.5 ). ${ }^{5}$

Information that women receive from healthcare providers significantly influences their contraception choices. Van Zijl et $a l^{6}$ demonstrated that there was a link between healthcare providers' knowledge and women's IUD uptake. They found that low usage of IUDs was related to lack of knowledge about this method among doctors. ${ }^{6}$ Hence, IUDs were not frequently discussed with women or suggested as a reliable contraceptive option. Other studies also suggested that provider knowledge was deficient in some aspects of contraception. For example, as reported by Harper et al, fewer than half of providers (nurses or physician assistants) in that study were aware of evidence-based guidelines for eligibility for IUDs. ${ }^{7}$

This study was designed to evaluate the knowledge as well as the attitudes and perception towards IUDs among doctors in Kuala Lumpur, the capital city of Malaysia, where access to health facilities is good. We also aimed to determine the practice pattern and identify factors associated with the practice of IUD use.

\section{METHODS}

In this cross-sectional questionnaire study, 400 doctors from government and private sectors were invited using a randomisation method. A list of doctors practising in Kuala Lumpur was intially generated, to include general practitioners, doctors in primary health clinics, and obstetrics and gynaecology specialists. Doctors were chosen randomly from the list by computer with equal representation from both the government and private sectors. A telephone call was made to acquire verbal consent before the questionnaire was mailed to the selected doctors. Informed consent was implied when the doctors completed the questionnaire and returned it. A second questionnaire was mailed to non-respondents after approximately 3 weeks. No incentive was provided.

The questionnaire was developed and validated based on literature research and personal discussion with a previous researcher. ${ }^{8}$ The overall reliability score using Cronbach's alpha was 0.769 . The questionnaire included 37 questions in four sections: (a) knowledge, (b) practice, (c) attitude and (d) perception toward personal efficacy in providing an IUD service.

Knowledge was assessed by eight questions: three multiple-choice questions (total score 3) and 17 truefalse questions (total score 17), making a total score of 20. A score of 15 and above was considered 'good', 10-14 considered 'average' while 9nine and below was categorised as 'poor'. Practice was assessed with a question about whether the individual had ever inserted an IUD during their career. With regard to current practice, the provider was asked to indicate whether they 'recommend (the IUD) to no one', 'recommend to selected clients and refer to other people' or 'recommend and insert it themselves'. Attitude/perception was assessed by closed-ended questions towards the preventing and promoting factors that may influence the decision to recommend the IUD. Providers were asked about their own perception of self-efficacy in providing an IUD service using a Likert scale. A total score of more than 15 was classified as a positive perception towards efficacy. All data were collected and analysed using SPSS Version 22.0 (Armonk, NY: IBM Corp.) This study was approved by the Universiti Kebangsaan Malaysia Research Ethics Committee.

\section{Patient and public involvement}

Patients were not involved in this study.

\section{RESULTS}

A total of 400 doctors were invited and 240 of them replied (after a reminder), giving a response rate of $60 \%$. Of the participants, $161(67.0 \%)$ were from the government sector and $79(33.0 \%)$ were from the private sector. The mean age of respondents was 33 years $(\mathrm{SD} \pm 7.3)$. Most respondents $(75.8 \%)$ were trained in IUD insertion, but significantly fewer private sector doctors had IUD training than government doctors $(55.0 \%$ vs $86.2 \%, \mathrm{P} \leq 0.001)$. Government doctors had more contraceptive options compared with private doctors. The availability of IUDs, as well as the total number of women requesting family planning services, was also significantly higher in the government sector. More than half of facilities had inserted at least one IUD per month. The proportion of facilities that did not insert an IUD in a month was higher in the private than the government settings ( $40.5 \%$ vs $20.5 \%)$.

The knowledge score among all the doctors studied was 'average' (as defined in Methods: score 10-14) with a mean score of 13.6 ( $\mathrm{SD} \pm 2.8$ ) from 20 questions, and 39.2\% had a 'good' score ( $\geq 15 / 20)$. Government doctors had a significantly higher knowledge score than those in the private sector $(14.0 \pm 2.8$ vs $12.7 \pm 2.8, \mathrm{P}=0.001)$. Table 1 summarises the doctors' general knowledge regarding IUDs. Only $30.8 \%$ of them could answer correctly regarding IUDs' Pearl index and the majority (68.1\%) were unaware that IUDs could be inserted within 48 hours postpartum. Knowledge regarding IUDs as emergency contraception (EC), return of fertility, and IUD insertion at 4 weeks after birth were all significantly better among government compared with private doctors. Linear regression analysis revealed that the number of patients seen in a typical week and number of contraception options available in the facilities were significantly associated with total knowledge of doctors (table 2).

The mean score for Medical Eligibility Criteria (MEC) was good (5.0/7.0 \pm 1.6$)$, with no significant difference between the two groups (table 3). Awareness of MEC was significantly higher among government 
Table 1 Doctors' correct answers for general knowledge about intrauterine devices

\begin{tabular}{|c|c|c|c|c|}
\hline \multirow[b]{2}{*}{ Variables } & \multicolumn{2}{|l|}{ Sector } & \multirow[b]{2}{*}{$\begin{array}{l}\text { Total } \\
(n=240)\end{array}$} & \multirow[b]{2}{*}{ P value } \\
\hline & $\begin{array}{l}\text { Government } \\
(n=161)\end{array}$ & $\begin{array}{l}\text { Private } \\
(\mathrm{n}=79)\end{array}$ & & \\
\hline $\begin{array}{l}\text { Maximum length of time a woman can use Multiload Cu } 375 \text { IUD after } \\
\text { insertion }\end{array}$ & $74(46.3)$ & $38(47.5)$ & $112(46.7)$ & 0.855 \\
\hline Effectiveness of the IUD (Pearl index) & $54(33.8)$ & $20(25.0)$ & $74(30.8)$ & 0.166 \\
\hline Return of fertility & $134(83.8)$ & $53(66.3)$ & $187(77.9)$ & 0.002 \\
\hline IUD can be used as emergency contraception & $124(77.5)$ & $42(52.5)$ & $166(69.2)$ & $<0.001$ \\
\hline IUD increased risk of ectopic pregnancy & $73(45.6)$ & $27(33.8)$ & $100(41.7)$ & 0.079 \\
\hline \multicolumn{5}{|l|}{ Timing of IUD insertion } \\
\hline Any time during the menstrual cycle & $101(63.1)$ & $47(58.8)$ & $148(64.7)$ & 0.511 \\
\hline Within 48 hours postpartum & $51(31.9)$ & $23(28.7)$ & $74(30.8)$ & 0.621 \\
\hline Up to 7 days postpartum & $113(70.6)$ & $56(70.0)$ & $169(70.4)$ & 0.920 \\
\hline 4 weeks after delivery & $145(90.6)$ & $60(75.0)$ & $205(85.4)$ & 0.001 \\
\hline \multicolumn{5}{|l|}{ Side effects/adverse outcomes } \\
\hline Headache & $147(91.9)$ & $71(88.8)$ & $218(90.8)$ & 0.429 \\
\hline Ectopic pregnancy & $122(76.3)$ & $61(76.3)$ & $183(76.3)$ & 1.000 \\
\hline Increase weight & $150(93.8)$ & $73(91.3)$ & $223(92.9)$ & 0.477 \\
\hline Migration & $136(85.0)$ & $61(76.3)$ & $197(82.1)$ & 0.096 \\
\hline \multicolumn{5}{|l|}{ Suitability for IUD } \\
\hline History of PID a year ago and currently asymptomatic & $60(37.5)$ & $30(37.5)$ & $90(37.5)$ & 1.000 \\
\hline History of spontaneous first-trimester abortion & $117(73.1)$ & $57(71.3)$ & $174(72.5)$ & 0.759 \\
\hline History of ectopic pregnancy previously & $81(50.6)$ & $31(36.8)$ & $112(46.7)$ & 0.082 \\
\hline Breastfeeding & $155(96.9)$ & $74(92.5)$ & $229(95.4)$ & 0.230 \\
\hline Diabetes mellitus & $135(84.4)$ & $62(77.5)$ & $197(82.1)$ & 0.190 \\
\hline Ischaemic heart disease & $129(80.6)$ & $65(81.3)$ & $194(80.8)$ & 0.908 \\
\hline Obesity & $142(88.8)$ & 65 (81.3) & $207(86.3)$ & 0.112 \\
\hline
\end{tabular}

Data expressed in $\mathrm{n}(\%) ; \chi^{2}$.

IUD, intrauterine device; PID, pelvic inflammatory disease.

doctors. A simple linear regression analysis showed that there was a positive correlation between total MEC score and MEC awareness $(F=6.151, P=0.014)$, with $\mathrm{R}^{2}=0.025$. The MEC score increased by 0.346 with every increment in MEC awareness. Knowledge of doctors correlated well with the level of previous training (OR $0.318,95 \% \mathrm{CI} 0.16$ to $0.64, \mathrm{P}=0.001$ ). Simple linear regression showed a significant

Table 2 Analysis model for factors associated with knowledge score

\begin{tabular}{|c|c|c|c|c|}
\hline \multirow[b]{2}{*}{ Variables } & \multicolumn{3}{|c|}{ Linear regression } & \multirow[b]{2}{*}{$P$ value } \\
\hline & B-coefficient & t-test & $95 \% \mathrm{Cl}$ & \\
\hline Knowledge score (constant) & & 6.16 & 7.68 to 14.89 & $<0.001$ \\
\hline Age & 0.019 & 0.132 & -0.102 to 0.117 & 0.895 \\
\hline Gender & -0.035 & -0.568 & -1.028 to 0.568 & 0.571 \\
\hline Working experience & 0.276 & 3.638 & 0.596 to 2.004 & 0.093 \\
\hline Working duration & -0.002 & -0.016 & -0.010 to 0.010 & 0.988 \\
\hline Number of patients seen/week & 0.127 & 2.045 & 0.001 to 0.057 & 0.042 \\
\hline Type of contraception & 0.204 & 2.456 & 0.055 to 0.501 & 0.015 \\
\hline Availability of IUDs in facility & -0.051 & -0.619 & -1.391 to 0.726 & 0.536 \\
\hline $\begin{array}{l}\text { Number of IUDs inserted/month in the working } \\
\text { facility }\end{array}$ & -0.067 & -1.031 & -0.520 to 0.163 & 0.303 \\
\hline
\end{tabular}


Table 3 Knowledge of Medical Eligibility Criteria among doctors

\begin{tabular}{|c|c|c|c|c|}
\hline \multirow[b]{2}{*}{ Characteristics } & \multicolumn{2}{|l|}{ Sector } & \multirow[b]{2}{*}{$\begin{array}{l}\text { Total } \\
(n=240)\end{array}$} & \multirow[b]{2}{*}{$P$ value } \\
\hline & $\begin{array}{l}\text { Government } \\
(n=161)\end{array}$ & $\begin{array}{l}\text { Private } \\
(n=79)\end{array}$ & & \\
\hline \multicolumn{5}{|l|}{${ }^{*}$ Correct answer MEC for IUD } \\
\hline History of PID a year ago and currently asymptomatic & $60(37.5)$ & $30(37.5)$ & $90(37.5)$ & 1.000 \\
\hline History of spontaneous first-trimester abortion & $117(73.1)$ & $57(71.3)$ & $174(72.5)$ & 0.759 \\
\hline History of ectopic pregnancy previously & $81(50.6)$ & $31(36.8)$ & $112(46.7)$ & 0.082 \\
\hline Breastfeeding & $155(96.9)$ & $74(92.5)$ & $229(95.4)$ & 0.230 \\
\hline Diabetes mellitus & $135(84.4)$ & $62(77.5)$ & $197(82.1)$ & 0.190 \\
\hline Ischaemic heart disease & $129(80.6)$ & $65(81.3)$ & $194(80.8)$ & 0.908 \\
\hline Obesity & $142(88.8)$ & $65(81.3)$ & $207(86.3)$ & 0.112 \\
\hline †Total MEC score & $5.1 \pm 1.6$ & $4.8 \pm 1.7$ & $5.0 \pm 1.6$ & 0.156 \\
\hline${ }^{*}$ Awareness of MEC & $107(66.9)$ & $29(36.2)$ & $136(56.7)$ & $<0.001$ \\
\hline
\end{tabular}

*Data expressed in $\mathrm{n}(\%) ; \chi^{2}$.

†Data expressed in mean (SD), t-test.

IUD, intrauterine device; MEC, Medical Eligibility Criteria; PID, pelvic inflammatory disease.

correlation between knowledge score and when the most recent training (within 6 months) had been received $(\mathrm{F}=20.182, \mathrm{P}=0.000)$, with a $\mathrm{R}^{2}=0.101$.

Adverse side effects commonly thought to be associated with IUDs such as ectopic pregnancy and pelvic inflammatory disease were more significant concerns among private doctors (table 4). About half of the private doctors (51.2\%) reported unavailability of IUDs in their working place. Otherwise, both government and private doctors agreed that the IUD was a good long-term method of contraception and easily reversible. More government doctors perceived IUDs as an effective contraceptive method compared with private doctors $(62.5 \%$ vs $45 \%)$.

\begin{tabular}{|c|c|c|c|c|}
\hline \multirow[b]{2}{*}{ Variables } & \multicolumn{2}{|l|}{ Sector } & \multirow[b]{2}{*}{$\begin{array}{l}\text { Total } \\
(\mathrm{n}=240)\end{array}$} & \multirow[b]{2}{*}{$P$ value } \\
\hline & $\begin{array}{l}\text { Government } \\
(n=161)\end{array}$ & $\begin{array}{l}\text { Private } \\
(\mathrm{n}=79)\end{array}$ & & \\
\hline \multicolumn{5}{|l|}{ Side effects which prevent recommendation of IUDs to patients } \\
\hline Risk of perforation & $67(41.9)$ & $48(60.0)$ & $115(47.9)$ & 0.008 \\
\hline Heavy menstrual bleeding & $102(63.7)$ & $43(53.8)$ & $145(60.4)$ & 0.135 \\
\hline Increased risk of malignancy & $18(11.3)$ & $10(12.5)$ & $28(11.7)$ & 0.776 \\
\hline Increased risk of ectopic pregnancy & $59(36.9)$ & $55(68.8)$ & $114(47.5)$ & $<0.001$ \\
\hline Increased risk of acquiring PID & $75(46.9)$ & $51(63.7)$ & $126(52.5)$ & 0.014 \\
\hline \multicolumn{5}{|l|}{$\begin{array}{l}\text { Factors/characteristics which negatively influence IUD } \\
\text { recommendation }\end{array}$} \\
\hline Not available in their clinic/not adequate supply in their clinic & $49(30.6)$ & $41(51.2)$ & $90(37.5)$ & 0.002 \\
\hline Need extra time for counselling & $22(13.8)$ & $12(17.5)$ & $36(15.0)$ & 0.793 \\
\hline It is expensive for clients & $9(5.6)$ & $11(13.8)$ & $20(8.3)$ & 0.032 \\
\hline The side effects are too great & $11(6.9)$ & $7(8.8)$ & $18(7.5)$ & 0.603 \\
\hline Favour other method & $48(30.0)$ & $33(41.3)$ & $81(33.8)$ & 0.082 \\
\hline \multicolumn{5}{|l|}{ Factors or features that promote IUD recommendation } \\
\hline It is a long-term method & $137(85.6)$ & $64(80.0)$ & $201(83.8)$ & 0.265 \\
\hline It is easily reversible & $121(75.6)$ & $55(68.8)$ & $176(73.3)$ & 0.256 \\
\hline It is being promoted by Ministry of Health & $76(47.5)$ & $32(40.0)$ & $108(45.0)$ & 0.271 \\
\hline It is a profitable method & $26(16.3)$ & $16(20.0)$ & $42(17.5)$ & 0.471 \\
\hline It is very effective & $100(62.5)$ & $36(45.0)$ & $136(56.7)$ & 0.010 \\
\hline
\end{tabular}

Data expressed in $\mathrm{n}(\%) ; \chi^{2}$.

IUD, intrauterine device; PID, pelvic inflammatory disease. 
Table 5 Analysis model for recommending and inserting intrauterine devices

\begin{tabular}{|c|c|c|c|c|}
\hline \multirow[b]{2}{*}{ Variables } & \multicolumn{3}{|c|}{ Logistic regression } & \multirow[b]{2}{*}{$P$ value } \\
\hline & B-coefficent & Adj B & $95 \% \mathrm{Cl}$ & \\
\hline Practice recommends and inserts IUDs (constant) & 2.565 & 13.003 & & 0.097 \\
\hline Gender & 0.299 & 1.348 & 0.615 to 2.959 & 0.456 \\
\hline \multicolumn{5}{|l|}{ Working experience } \\
\hline Generalists & 0.661 & 1.835 & 1.752 to 0.175 & 0.576 \\
\hline Specialists & 1.798 & 6.637 & 6.037 to 0.253 & 0.266 \\
\hline Working duration & 0.002 & 1.002 & 0.997 to 1.008 & 0.434 \\
\hline Number of patients seen/week & 0.038 & 1.039 & 1.004 to 1.075 & 0.028 \\
\hline Availability of IUDs in facility & -1.355 & 0.258 & 0.113 to 0.589 & 0.001 \\
\hline Been trained previously & -1.838 & 0.159 & 0.060 to 0.419 & $<0.001$ \\
\hline Perceived had sufficient knowledge & -0.847 & 0.429 & & 0.037 \\
\hline Aware of MEC & -0.481 & 0.618 & 0.297 to 1.288 & 0.199 \\
\hline \multicolumn{5}{|l|}{ Knowledge group } \\
\hline High knowledge & -1.709 & 0.181 & 0.040 to 0.821 & 0.027 \\
\hline Average/low knowledge & -1.877 & 0.153 & 0.037 to 0.624 & 0.009 \\
\hline
\end{tabular}

IUD, intrauterine device; MEC, Medical Eligibility Criteria.

As many as $62.5 \%$ of doctors perceived that they had sufficient information to counsel their clients about IUDs. A logistic regression analysis demonstrated that perception of the adequacy of IUD information was significantly correlated with the high knowledge score group (Adjust $\beta=0.151, \mathrm{P}=0.04,95 \% \mathrm{CI} 0.042$ to 0.540 ). The mean score of self-efficacy in providing an IUD service was high for both sectors: $22.19 \pm 3.50$ for government and $20.65 \pm 4.00$ for private doctors.

More than half of the doctors (54.2\%) would recommend and insert IUDs themselves. Government doctors were significantly more positive than private doctors $(60.2 \%$ vs $34.2 \%)$. Only a minority $(6.7 \%)$ of them did not recommend IUDs to women. Half of the private doctors $(50.6 \%)$ were likely to recommend IUDs, but referred their clients to other centres for IUD insertion. Multiple logistic regression analysis showed that doctors who were trained previously (OR 0.159, CI 95\% 0.060-0.419, $\mathrm{P} \leq 0.001$ ) and who perceived that they had sufficient knowledge would continue to recommend and insert IUDs themselves (OR 0.429, CI 95\% 0.194-0.949, $\mathrm{P}=0.037$ ) (table 5). This practice also was well correlated with the number of patients seen in a week and availability of IUDs in their working facility. Gender, working experience, sector, as well as MEC awareness, did not appear to influence the current practice of recommendation and insertion of IUDs.

\section{DISCUSSION}

This is the first study to explore the knowledge and practice of intrauterine contraception among Malaysian doctors. Most previous studies compared contraception providers by different departments, such as gynaecologists versus primary health clinicians.
The results from our study suggest that a significant gap exists among government and private doctors' knowledge and practice in relation to providing IUD services, especially regarding the efficacy of IUDs. Only $45 \%$ of private doctors and $63 \%$ of government doctors believed that the IUD is an effective contraceptive method.

Our findings were similar to those of previous studies conducted in other countries. ${ }^{7-9}$ Objectively, our study was an adaptation from a survey among nurses as contraception providers in Nepal. ${ }^{8}$ Surprisingly, our results showed a lower percentage of all correct answers, suggesting a serious knowledge gap among our doctors. However, our doctors' knowledge of intrauterine contraception was better compared with studies conducted in other developing countries. ${ }^{9}$ The rate of correct answers was lower among the private doctors as compared with government doctors for almost all sections of questions and was particularly varied in the total knowledge score. In contrast, studies elsewhere reported that private doctors shared similar levels of knowledge to public doctors. ${ }^{8}{ }^{10}$ In Malaysia it is known that doctors from the public sector are more likely to receive continuing medical education and to attend professional development meetings. This increases sharing and interchange of information with other healthcare professionals. In contrast, we believe that most of the private doctors run their clinics independently. They may have less contact with the latest research outcomes and guidelines related to contraceptive practice.

Training is indeed an important predictor of knowledge scores as well as current practice among doctors. We found that knowledge was directly related to previous training received and was well correlated 
with the perception of sufficient knowledge. Doctors who have been trained with IUD workshops or courses may have higher knowledge scores, and are more likely to recommend and to insert the IUDs themselves and have higher self-efficacy scores. Previous studies have demonstrated that practitioners who had continuing training programmes had higher levels of confidence. ${ }^{11}$ It has been suggested that doctors who insert IUDs need to insert at least 12 IUDs per year to maintain their skills and confidence levels. ${ }^{12}$

We demonstrated that knowledge level was significantly associated with the number of contraceptive methods provided in a facility. This finding was similar to the study outcome in Nepal. ${ }^{8}$ The providers' knowledge also correlates to the workload of the facility, which is translated into the number of patients seen per week. This evidence supports the theory that knowledge increments are proportional to the exposure to patients. ${ }^{13}$

We found that a large proportion of doctors were unaware of the option of IUD insertion within 48 hours after childbirth. To date, there is no clinical practice guideline regarding IUD insertion in Malaysia. Generally, IUD insertion is done at 6 weeks postpartum. Post-placental IUD insertion has been introduced as women are often highly motivated for contraception at the time of birth, and the discomfort of insertion is minimal. ${ }^{14}{ }^{15}$ It has been shown to be safe and acceptable to women and is a promising area for future research and practice. ${ }^{14-17}$ Efforts should be made to promote post-placental IUD insertion among Malaysian doctors. Research has documented unintended pregnancy during the 6-week waiting period for insertions after childbirth. ${ }^{16}$ Up to $40 \%$ of women requesting IUDs are lost during this period, sometimes because providers counsel against IUD usage (16\%). ${ }^{718}$

We would like to highlight the survey result on use of IUDs for EC as studies have shown that the method can be used safely up to 5 days after unprotected intercourse. ${ }^{19}{ }^{20}$ In our study, $69.2 \%$ of the doctors were aware that IUD can be used as EC. The rate is higher compared with a study in Egypt when the reported knowledge of IUD as EC was only $40.7 \%{ }^{21}$ However, even though the result is good we did not assess whether our local doctors actually recommend or insert IUDs as EC. Harper et al reported that the majority of contraceptive providers (85\%) in California had never recommended the copper IUD for EC despite having good knowledge. ${ }^{22}$ As EC, the IUD can reduce unintended pregnancy by up to $99 \%$ and some have reported higher efficacy compared with oral levonorgestrel or ulipristal acetate. ${ }^{1923}$

The availability of IUD services in the government sector is higher than in the private sector as it is funded by the government as a means to increase the contraceptive prevalence rate among women. Although $81.9 \%$ of the government doctors reported the availability of IUDs in their premises, only $60.2 \%$ would recommend and insert IUDs themselves. This indicates that other factors may influence practice such as knowledge and perceptions towards IUDs. A systematic review reported that the healthcare provider's attitude had a strong influence on the rate of IUD usage. ${ }^{24}$ The likelihood of prescribing the IUD depends on many factors, including providers' basic knowledge, their training in insertion or removal of IUDs, and the level of patients' counselling.

This study suggests that ongoing training and interval supervision are needed to reduce knowledge deficiency among Malaysian doctors, particularly in the private sector. Translating evidence regarding safety and efficacy of IUDs from clinical trials into daily practice is not an easy task. Evidence must be widely distributed and promoted to increase awareness among doctors. Educational meetings alone or combined with other interventions may improve professional practice and healthcare outcomes for patients. Otherwise, practice will never change.

\section{LIMITATIONS OF THE STUDY}

Our study had some limitations. It focused on doctors from a single city and it had a relatively small sample size due to its suboptimal response rate. Consequently the findings of this study should not be generalised to medical practice elsewhere in Malaysia with different settings and different access to health facilities.

\section{CONCLUSION}

This study demonstrates that in Malaysia there is still a knowledge and practice gap regarding intrauterine contraception among government and private doctors. The evidence highlights the need for more educational and campaign programmes, focusing particularly on private doctors, to bridge the disparity of provision of IUD services.

Acknowledgements The authors would like to convey special thanks to Dr N M Chakraborty who allowed them to reproduce the Nepal questionnaire and modify it to suit their local setting.

Contributors NS was responsible for data collection and analysis in this study. CKT was involved in the study design and final manuscript writing. MAA was involved in the study design. AKAK was involved in the study design and final review of the manuscript.

Funding The authors have not declared a specific grant for this research from any funding agency in the public, commercial or not-for-profit sectors.

Competing interests None declared.

Patient consent Not required.

Ethics approval Confidentiality and anonymity were assured by the use of a coded system for the questionnaires and also during data analysis. This information was only accessible to the researchers. This study was approved by the UKM Research Ethics Committee.

Provenance and peer review Not commissioned; externally peer reviewed. 
(C) Article author(s) (or their employer(s) unless otherwise stated in the text of the article) 2018. All rights reserved. No commercial use is permitted unless otherwise expressly granted.

\section{REFERENCES}

1 Alkema L, Kantorova V, Menozzi C, et al. National, regional, and global rates and trends in contraceptive prevalence and unmet need for family planning between 1990 and 2015: a systematic and comprehensive analysis. Lancet 2013;381:1642-52.

2 Najimudeen M, Sachchithanantham K. An insight into low contraceptive prevalence in Malaysia and its probable consequences. Int J Reprod Contracept Obstet Gynecol 2017;3:493-6.

3 Ahmed S, Li Q, Liu L, et al. Maternal deaths averted by contraceptive use: an analysis of 172 countries. Lancet 2012;380:111-25.

4 Stoddard A, McNicholas C, Peipert JF. Efficacy and safety of long-acting reversible contraception. Drugs 2011;71:969-80.

5 Ahmad N, Tey N, Kamarul Zaman K, et al. Status of family planning in Malaysia. In: Family planning in Asia and Pacific Region. Thailand: National Population and Family Development Board (NPFDB) Bangkok, 2010.

6 van Zijl S, Morroni C, van der Spuy ZM. A survey to assess knowledge and acceptability of the intrauterine device in the Family Planning Services in Cape Town, South Africa. J Fam Plann Reprod Health Care 2010;36:73-8.

7 Harper CC, Blum M, de Bocanegra HT, et al. Challenges in translating evidence to practice: the provision of intrauterine contraception. Obstet Gynecol 2008;111:1359-69.

8 Chakraborty NM, Murphy C, Paudel M, et al. Knowledge and perceptions of the intrauterine device among family planning providers in Nepal: a cross-sectional analysis by cadre and sector. BMC Health Serv Res 2015;15:39.

9 Hoffman SJ, Guindon GE, Lavis JN, et al. Clinicians' knowledge and practices regarding family planning and intrauterine devices in China, Kazakhstan, Laos and Mexico. Reprod Health 2016;13:70.

10 Landry DJ, Wei J, Frost JJ. Public and private providers' involvement in improving their patients' contraceptive use. Contraception 2008;78:42-51.

11 Stewart M, Digiusto E, Bateson D, et al. Outcomes of intrauterine device insertion training for doctors working in primary care. Aust Fam Physician 2016;45:837.
12 Black KI, Sakhaei T, Garland SM. A study investigating obstetricians' and gynaecologists' management of women requesting an intrauterine device. Aust N Z J Obstet Gynaecol 2010;50:184-8.

13 Agha S, Fareed A, Keating J. Clinical training alone is not sufficient for reducing barriers to IUD provision among private providers in Pakistan. Reprod Health 2011;8:40.

14 Grimes DA, Lopez LM, Schulz KF, et al. Immediate postpartum insertion of intrauterine devices. Cochrane Database Syst Rev 2010;5:CD003036.

15 Kapp N, Curtis KM. Intrauterine device insertion during the postpartum period: a systematic review. Contraception 2009;80:327-36.

16 Kittur S, Kabadi Y. Enhancing contraceptive usage by postplacental intrauterine contraceptive devices (PPIUCD) insertion with evaluation of safety, efficacy, and expulsion. Int J Reprod Contracept Obstet Gynecol 2016;1:26-32.

17 Levi E, Cantillo E, Ades V, et al. Immediate postplacental IUD insertion at cesarean delivery: a prospective cohort study. Contraception 2012;86:102-5.

18 Ogburn JA, Espey E, Stonehocker J. Barriers to intrauterine device insertion in postpartum women. Contraception 2005;72:426-9.

19 Wu S, Godfrey EM, Wojdyla D, et al. Copper T380A intrauterine device for emergency contraception: a prospective, multicentre, cohort clinical trial. BJOG 2010;117:1205-10.

20 Harrison-Woolrych M, Ashton J, Coulter D. Uterine perforation on intrauterine device insertion: is the incidence higher than previously reported? Contraception 2003;67:53-6.

21 Ibrahim ZM, Ahmed MR, Shaaban MM. Knowledge, attitude and practice of emergency contraception among health care providers in Ismailia, Egypt. Middle East Fertil Soc J 2013;18:246-52.

22 Harper CC, Speidel JJ, Drey EA, et al. Copper intrauterine device for emergency contraception: clinical practice among contraceptive providers. Obstet Gynecol 2012;119(2 Pt 1):220.

23 Glasier AF, Cameron ST, Fine PM, et al. Ulipristal acetate versus levonorgestrel for emergency contraception: a randomised non-inferiority trial and meta-analysis. Lancet 2010;375:555-62.

24 Buhling KJ, Zite NB, Lotke P, et al. Worldwide use of intrauterine contraception: a review. Contraception 2014;89:162-73. 